\title{
Dose-Dependent Modulation of Choroidal Neovascularization by Plasminogen Activator Inhibitor Type I: Implications for Clinical Trials
}

\author{
Vincent Lambert, ${ }^{1}$ Carine Munaut, ${ }^{1}$ Peter Carmeliet, ${ }^{2}$ Robert D. Gerard, ${ }^{3}$ Paul J. Declerck, ${ }^{4}$ \\ Ann Gils, ${ }^{4}$ Carel Claes, ${ }^{5}$ Jean-Michel Foidart, ${ }^{1}$ Agnès Noël, ${ }^{1}$ and Jean-Marie Rakic ${ }^{6}$
}

Purpose. To explain the conflicting reports about the influence of plasminogen activator inhibitor type (PAI-1) on pathologic angiogenesis, such as occurs during the exudative form of age-related macular degeneration.

Methods. The expression of PAI-1 mRNA was analyzed in human and murine choroidal neovascularization (CNV) by RTPCR. The influences of increasing doses of recombinant PAI-1 were evaluated by daily intraperitoneal injections in PAI-1 ${ }^{-/-}$ and wild-type animals with a model of laser-induced CNV. The double mechanism of action of PAI-1 (proteolytic activity inhibition versus vitronectin binding) was explored by immunohistochemical localization of fibrinogen/fibrin and by injection of recombinant PAI-1 protein defective for vitronectin binding or with adenoviral vectors bearing a mutated binding-deficient PAI-1 gene.

Results. PAI-1 expression was present in human CNV and strongly induced in the course of experimental subretinal neovascularization. Daily injections of recombinant PAI-1 proteins in control and PAI-1 ${ }^{-/-}$animals demonstrated that PAI-1 could exhibit both pro- and antiangiogenic effects, dependent on the dose. PAI-1 mutants defective for vitronectin binding were used to show that PAI-1 promotes choroidal pathologic angiogenesis merely through its antiproteolytic activity.

From the ${ }^{1}$ Laboratory of Tumor and Development Biology, University of Liège, Liège, Belgium; the ${ }^{2}$ Center for Transgene Technology and Gene Therapy, and ${ }^{4}$ Pharmaceutical Biology and Phytopharmacology, Katholieke Universiteit Leuven, Leuven, Belgium; the ${ }^{3}$ Departments of Internal Medicine and Molecular Biology, University of Texas Southwestern Medical Center, Dallas, Texas; the ${ }^{5}$ Department of Ophthalmology, Middelheim Hospital, Antwerp, Belgium; and the ${ }^{6}$ Department of Ophthalmology, University Hospital, Liège, Belgium.

Supported by grants from Les Amis des Aveugles, Ghlin, Belgium; the Commission of European Communities; the Fonds de la Recherche Scientifique Médicale; the National Fund for Scientific Research (FNRS, Belgium); the Fédération Belge Contre le Cancer; the FB Assurances; the Fondation Léon Frédéricq (University of Liège); the Fonds d'Investissements de la Recherche Scientifique (CHU, Liège, Belgium); and the Interuniversity Attraction Poles (IUAP) from the Federal Office for Scientific, Technical and Cultural Affairs (OSTC, Brussels, Belgium). $\mathrm{CM}$ is a research associate and $\mathrm{AN}$ is a senior research associate from the National Fund for Scientific Research (FNRS), Belgium. AG is a postdoctoral fellow of the Fund for Scientific Research (FWO, Vlaanderen, Belgium).

Submitted for publication November 18, 2002; revised January 13, 2003; accepted January 30, 2003.

Disclosure: V. Lambert, None; C. Munaut, None; P. Carmeliet, None; R.D. Gerard, None; P.J. Declerck, None; A. Gils, None; C. Claes, None; J.-M. Foidart, None; A. Noël, None; J.-M. Rakic, None

The publication costs of this article were defrayed in part by page charge payment. This article must therefore be marked "advertisement" in accordance with 18 U.S.C. $\$ 1734$ solely to indicate this fact.

Corresponding author: Jean-Marie Rakic, Department of Ophthalmology, University Hospital, Sart-Tilman, 4000 Liège, Belgium; jmrakic@chu.ulg.ac.be.
Conclusions. These observations may help to reconcile reports with opposite results regarding the effects of PAI-1 on angiogenesis and certainly warn against uncontrolled use of PAI-1modulating drugs in clinical trials. (Invest Opbthalmol Vis Sci. 2003;44:2791-2797) DOI:10.1167/iovs.02-1179

S everal studies have demonstrated that the absence of plas$\checkmark$ minogen activator inhibitor type I (PAI-1) in genetically modified (knockout) mice prevents the development of tumoral angiogenesis. ${ }^{1,2}$ PAI-1, through its inhibition of uPA (urokinase-type plasminogen activator) and tPA (tissue-type plasminogen activator) is a key regulator of the plasminogen system, a proteolytic cascade implicated in various physiological and pathologic processes including vascular thrombolysis, inflammation, wound healing, tumor invasion, and neovascularization. ${ }^{3-6}$ Also, through its capacity to interact with uPAR (uPA cellular receptor), vitronectin, and integrins, PAI-1 may also control cell migration. ${ }^{7,8}$

That PAI-1 presence was a necessary condition for angiogenesis was also observed in a model of laser-induced murine choroidal neovascularization (CNV). This model, while not associated with abnormal deposit component (drusen), encompasses several features of the exudative form of age-related macular degeneration (AMD), such as the trauma at the level of the Bruch's membrane, the involvement of mononuclear cells, the choroidal origin of new vessels and similar angiographic aspects. ${ }^{9,10}$ Analysis of corneal angiogenesis models induced by basic fibroblast growth factor corroborated the resistance of PAI- $1^{-/-}$mice to neovascularization. ${ }^{2}$

By contrast, others groups have in different experimental settings paradoxically suggested an inhibitory effect of high levels of PAI-1 on angiogenesis. Tumor cells transduced with PAI-1 CDNA showed a reduction in primary tumor growth and tumor-associated angiogenesis. ${ }^{11}$ The inhibitory effect of angiostatic steroids on neovascularization was attributed to a decrease in the expression of uPA (urokinase-type plasminogen activator) and an increase in the expression of PAI-1. ${ }^{12-14}$ The efficiency of one of these compounds (anecortave acetate) in inhibiting human $\mathrm{CNV}$ is currently the subject of phase II and phase III clinical trials involving hundreds of patients (Slakter JS, Singerman LJ, Yannuzzi LA, Russell SR, Hudson HL, Jerdan J, Zilliox P, Robertson S, ARVO Abstract 2909, 2002). Curiously, initial data suggest that whereas the smaller dosage of anecortave (15-mg periocular injection) seems much more efficient than placebo, the higher dose (30-mg injection) is ineffective. ${ }^{15} \mathrm{~A}$ biphasic dose-response curve was indeed observed in different in vitro (aortic rings) and in vivo (synthetic basements membrane [Matrigel; BD Labware, Bedford, MA] and chick chorioallantoic membrane $[\mathrm{CAM}]$ assays) models. ${ }^{16-18}$ One explanation that reconciles these apparently conflicting results suggests that PAI-1 may have both pro- and antiangiogenic activities, depending on its concentration.

To test that hypothesis in vivo in a model of pathologic angiogenesis more relevant to ocular disease, we first evaluated the presence or absence of PAI-1 mRNA in human CNV mem- 
branes, and then assessed the spatial and temporal expression profiles in murine laser-induced CNV. In the second phase, the influence of experimentally manipulated PAI-1 levels on murine $\mathrm{CNV}$ was explored, using daily intraperitoneal injections of recombinant PAI-1. Finally, we used an adenoviral delivery system to deliver mutated PAI-1 with defective vitronectin binding and normal proteolytic function, to dissect the mechanism of PAI-1 activity.

\section{Materials ANd Methods}

\section{RT-PCR Analysis of Human and Murine Neovascular Membranes}

The methods conformed to the tenets of the Declaration of Helsinki for research involving human subjects. Submacular CNV specimens were completely removed during surgery for $360^{\circ}$ macular translocation in patients with exudative AMD that was not amenable to conventional laser or photodynamic therapy. The specimens were immediately frozen in liquid nitrogen and stored at $-80^{\circ} \mathrm{C}$ until RT-PCR analysis.

At selected intervals (days 3-40) after laser induction in mice (described later), choroidal neovascular membranes and adjacent neural retina intact regions were separately extracted from frozen sections by laser capture microdissection (laser pressue catapulting [LPC] technique) as previously described. ${ }^{10}$ The specimens were covered with $100 \mu \mathrm{L}$ lysis buffer, and total RNA isolation was performed with a kit (PUREscript RNA Isolation Kit; BIOzym, Landgraaf, The Netherlands), according to the manufacturer's protocol.

The frozen murine and human tissues were first pulverized using a dismembrator (B. Braun Biotech International, GmBH, Melsungen, Germany) and total RNA was extracted with a kit (RNeasy; Quiagen, Paris, France) according to the manufacturer's protocol. $28 \mathrm{~S}$ rRNA was amplified with an aliquot of 10 ng of total RNA, with a reverse transcriptase RNA PCR kit (GeneAmp Thermostable rTth; Applied Biosystems, Foster City, CA) and two pairs of primers (identical for human and murine; sense: 5'-GTTCACCCACTAATAGGGAACGTGA-3' and reverse: 5'-GGATTCTGACTTAGAGGCGTTCAGT-3' for 28S mRNA; and sense: 5'-AGGGCTTCATGCCCCACTTCTTCA-3' and reverse: 5'-AGTAGAGGGCATTCACCAGCACCA-3' for PAI-1 (Eurogentec, Liège, Belgium). Reverse transcription was performed at $70^{\circ} \mathrm{C}$ for 15 minutes followed by a 2-minute incubation at $95^{\circ} \mathrm{C}$ for denaturation of RNA-DNA heteroduplexes. Amplification (33 cycles for PAI-1 and 19 cycles for 28S, or 45 cycles for PAI- 1 and 35 cycles for $28 S$ in the case of LPC material) started by a cycle of 15 seconds at $94^{\circ} \mathrm{C}, 20$ seconds at $60^{\circ} \mathrm{C}$ and 10 seconds at $72^{\circ} \mathrm{C}$. RT-PCR products were resolved on $2 \%$ agarose gels and analyzed with a fluorescence imager (Fluor-S MultiImager; Bio-Rad, Richmond, CA) after staining with ethidium bromide (FMC BioProducts, Philadelphia, PA). The expected size for RT-PCR products was 212 bp for $28 \mathrm{~S}$ and 197 bp for PAI-1.

\section{Murine Model of Laser-Induced Choroidal Neovascularization}

Homozygous PAI-1-deficient mice (PAI- $1^{-I^{-}}$) and the corresponding wild-type mice (WT or PAI- $1^{+/+}$) of either sex, 2 to 4 months old, with a mixed genetic background of $87 \%$ C57BL/6 and 13\% 129 strain, were used throughout the study. ${ }^{19}$ The animals were maintained with a 12-hour light-dark cycle and had free access to food and water. Animal experiments were performed in compliance with the ARVO Statement for the Use of Animals in Ophthalmic and Vision Research.

CNV was induced in mice by four burns (usually at the 6, 9, 12, and 3 o'clock positions around the optic disc) with a green argon laser (532 $\mathrm{nm}, 50-\mu \mathrm{m}$ diameter spot size; 0.05 -second duration, $400 \mathrm{~mW}$ ) as previously described. ${ }^{20}$ Mice with hemorrhaging or that did not exhibit an evident bubble at the site of every laser impact (the sign of a ruptured Bruch's membrane) were excluded from further analysis. Included animals (five or more in each condition) were killed at day 14 (except for spatial and temporal mRNA profiles). Before death, fluo- rescein angiograms (intraperitoneal injection of $0.3 \mathrm{~mL}$ of $1 \%$ fluorescein sodium; Ciba, Mechelen, Belgium) were performed to confirm that laser burns were showing late-phase increasing hyperfluorescent spots (corresponding to the leakage of fluorescein from newly formed permeable capillaries). The eyes were then enucleated and either fixed in buffered 3.5\% formalin solution for routine histology or embedded in optimal cutting temperature compound (Tissue TeK; Miles Laboratories, Naperville, IL) and frozen in liquid nitrogen for cryostat sectioning. CNV was quantified as previously described. ${ }^{9,10}$ Briefly, frozen serial sections were cut throughout the entire extent of each burn, and the thickest region (minimum of five per lesion) selected for the quantification. Using a computer-assisted image-analysis system (Micro Image version 3.0 for Windows 95/NT; Olympus Optical Co. Europe $\mathrm{GmbH}$, Birkeroed, Denmark), we estimated neovascularization by the ratio $(\mathrm{B} / \mathrm{C})$ of the thickness from the bottom of the pigmented choroidal layer to the top of the neovascular membrane (B) to the thickness of the intact-pigmented choroid adjacent to the lesion (C). A mean B/C ratio was determined for each laser impact.

\section{Immunohistochemistry}

Cryostat sections ( $5 \mu \mathrm{m}$ thick) were fixed in paraformaldehyde $1 \%$ in $0.07 \mathrm{M}$ phosphate-buffered saline (PBS; $\mathrm{pH} 7.0$ ) for 5 minutes or in acetone for 10 minutes at room temperature and then incubated with the primary antibody. Antibodies raised against mouse platelet endothelial cell adhesion molecule (PECAM; rat monoclonal, diluted 1:20; PharMingen, San Diego, CA), and murine fibrinogen/fibrin (diluted 1:400, goat polyclonal antibody; Nordic Immunologic, Tilburg, The Netherlands) were incubated for 1 hour at room temperature. The sections were washed in PBS (three times, 10 minutes each) and appropriate secondary antibody conjugated to horseradish peroxidase (HRP), or tetramethylrhodamine isothiocyanate (TRITC) were added: rabbit anti-goat IgG (diluted 1/100; Dako, Glostrup, Denmark) and rabbit anti-rat IgG (diluted 1/40; Sigma-Aldrich, St. Louis, MO) were applied for 30 minutes. For immunostaining of fibrinogen/fibrin, a drop of 3-amino-9-ethylcarbazole $\left(\mathrm{AEC}^{+}\right.$; Dako) was added, and sections were counterstained for 1 minute in hematoxylin. For immunofluorescence staining, after three washes in PBS for 10 minutes each and a final rinse in $10 \mathrm{mM}$ Tris- $\mathrm{HCl}$ buffer $(\mathrm{pH} 8.8)$, labeling was analyzed under an inverted microscope equipped with epifluorescence optics. Specificity of staining was assessed by substitution of nonimmune serum for primary antibody (not shown).

\section{Characterization of Active Recombinant PAI-1 and Mutants}

A stable PAI-1 variant referred to as PAI-1-stab, harboring the mutations Asn150His, Lys154Thr, Gln301Pro, Gln319Leu, and Met354Ile and demonstrating a functional half-life of approximately 150 hours, was produced as described ${ }^{21}$ and used in all experiments in which active recombinant PAI-1 was indicated. The mutant PAI-1-stab-Q123K (with impaired vitronectin binding properties), was created by a method based on a mutagenesis kit (Quickchange Site-Directed Mutagenesis Kit; Stratagene, La Jolla, CA) using pIGE20-PAI-stab as template and the appropriate synthetic oligonucleotide (i.e., 5'-CGGTCAAGAAAGTGGACTTTTCAGAGG-3', and its complementary oligonucleotide) for introduction of the Q123K mutation. PAI-1-stab and its variant were expressed and purified as described. ${ }^{22}$ Binding of PAI-1-stab-Q123K to murine vitronectin was 40 times lower than that observed with PAI-1stab. WT and PAI-1 ${ }^{-\prime-}$ mice were injected intraperitoneally daily with 10 or $100 \mu \mathrm{g}$ rPAI-1 or $100 \mu \mathrm{g}$ PAI-1-stab-Q123k.

\section{Adenovirus-Mediated PAI-1 cDNA Transfer}

E1-deleted recombinant adenovirus vectors expressing wild-type human PAI-1 (AdCMVPAI-1) or no transgene (AdRR5) were propagated as described previously. ${ }^{23,24}$ Recombinant viruses expressing mutant PAI-1 proteins AdCMVPAI-1 ${ }^{\text {Q123K }}$ were generated after substitution of a restriction fragment containing the desired mutation into the pACMVPAI-1 (wild type; WT) shuttle plasmid. PAI-1 with the Q123K muta- 

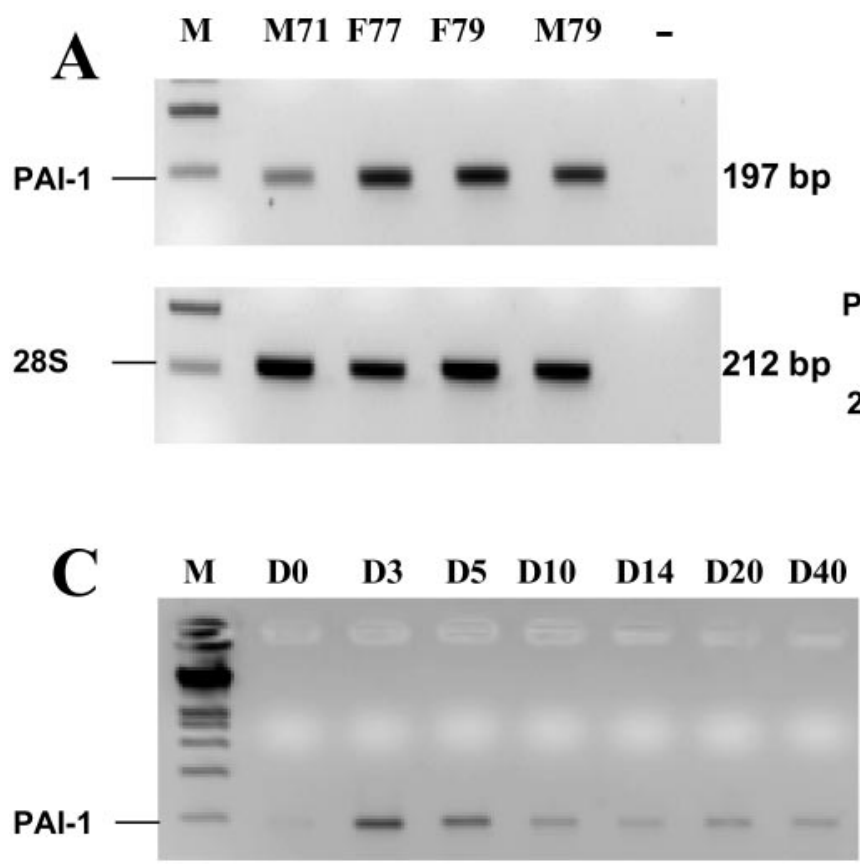

$28 \mathrm{~S}$

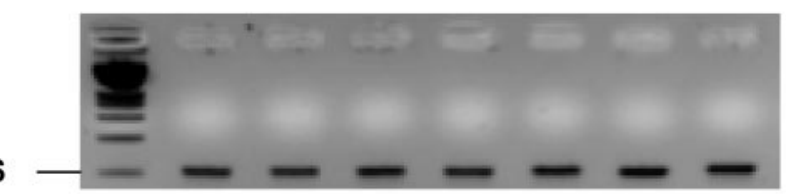

$197 \mathrm{bp}$

212 bp
B

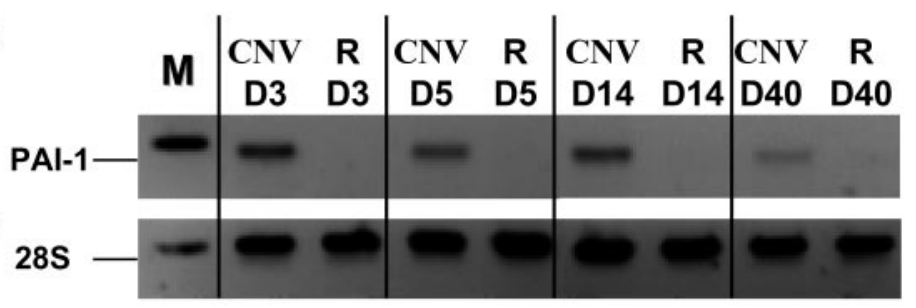

D

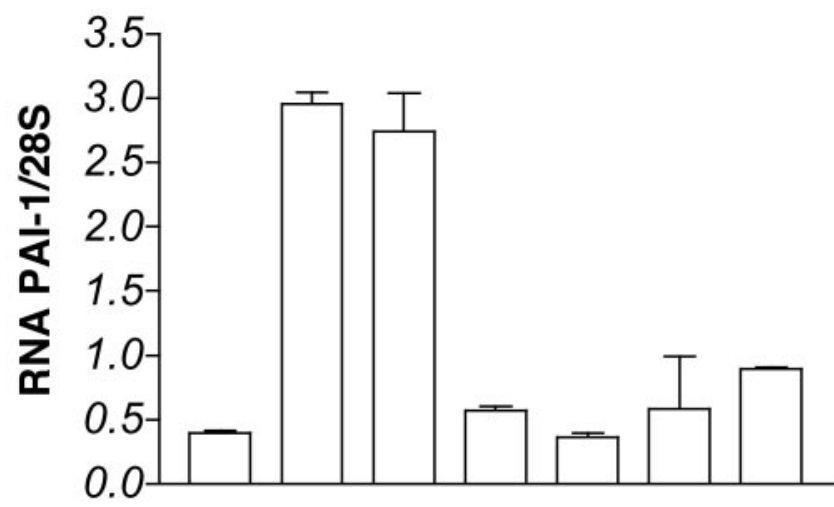

Time course

FIGURE 1. RT-PCR analysis of PAI-1 mRNA expression. (A) Representative example of PAI-1 mRNA expression in fresh surgically extracted choroidal neovascular membranes of four patients with exudative AMD (age in years is shown with gender). (B) Spatial profile of PAI-1 expression evaluated by RT-PCR on LPC-extracted murine experimental CNV at different intervals compared with the expression in intact adjacent neural retina (R). Histogram corresponding to the densitometric quantification of PAI-1 mRNA normalized to the 285 signal at different end points (D) with a representative gel (C). The evaluation was performed on the entire posterior segment after the induction of multiple wounds in Bruch's membrane. $28 \mathrm{~S}$ rRNA was used to assess the total amount of RNA loaded. M, molecular marker. The expected size of RT-PCR products is 197 bp for PAI-1 and 212 bp for 285.

tion had a specific 40-fold decrease in affinity for vitronectin, but retained full plasminogen inhibitory activity.

One day after CNV induction by laser, mice were intravenously injected with $200 \mu \mathrm{L}$ of control or recombinant adenovirus $\left(7 \times 10^{8}\right.$ plaque-forming units; PFU) encoding human PAI-1 (WT or mutant Q123K). The efficiency of transduction was evaluated with ELISA measurement of circulating PAI-1 levels and injection of adenoviruses encoding Escherichia coli $\beta$-galactosidase, as previously described (not shown). ${ }^{9,25}$ On day 14 , mice were killed, and eyes were excised and processed, as described earlier. According to regulatory constraints, the virally infected animals were permanently housed under BL3 (biohazard level 3) containment, and consequently fluorescein angiograms could not be performed.

\section{Statistical Analysis}

Data were analyzed on computer (Prism 3.0; GraphPad, San Diego, CA). The Mann-Whitney test was used to determine whether there were significant $(P<0.05)$ differences between different experimental conditions.

\section{Results}

\section{PAI-1 Expression Profile in Neovascular Membranes}

PAI-1 mRNA was detected in all human CNV specimens obtained during surgery (representative examples in Fig. 1A). Because these specimens can be mixed with RPE and/or neural retina elements, we evaluated the spatial distribution of PAI-1 mRNA within choroidal neovascular membranes, distinct from the adjacent retina, by using laser capture microdissection. We were unable to perform laser capture dissection on human specimens. Therefore, the procedure was used on laser-induced murine CNV membranes microdissected by LPC on frozen sections at different time end points (days 3-40 after laser). Evidence of PAI-1 mRNA expression was observed in WT mice at all time points studied (Fig. 1B), with an apparent decrease during the late stage (day 40 after laser treatment). The retinal specimens microdissected from neighboring intact areas remained negative for PAI-1 mRNA throughout the study period. To define more precisely the temporal pattern of gene expression, semiquantitative RT-PCR analysis (normalized to $28 \mathrm{~S}$ signal) was then applied on laser-induced murine neovascular choroidal membranes at different end points (days 3-40 after laser treatment). As shown in a densitometry histogram and on a representative gel (Figs. 1C, 1D), PAI-1 mRNA induction was substantial during the course of experimental murine $\mathrm{CNV}$, with a regression to basal level after day 10 (coinciding with the period of CNV stabilization).

\section{Dose-Dependent Effect of Recombinant PAI-1 on CNV}

CNV was evaluated in WT and PAI-1 ${ }^{-/-}$mice by immunostaining with anti-PECAM antibodies and, histologically, by measur- 

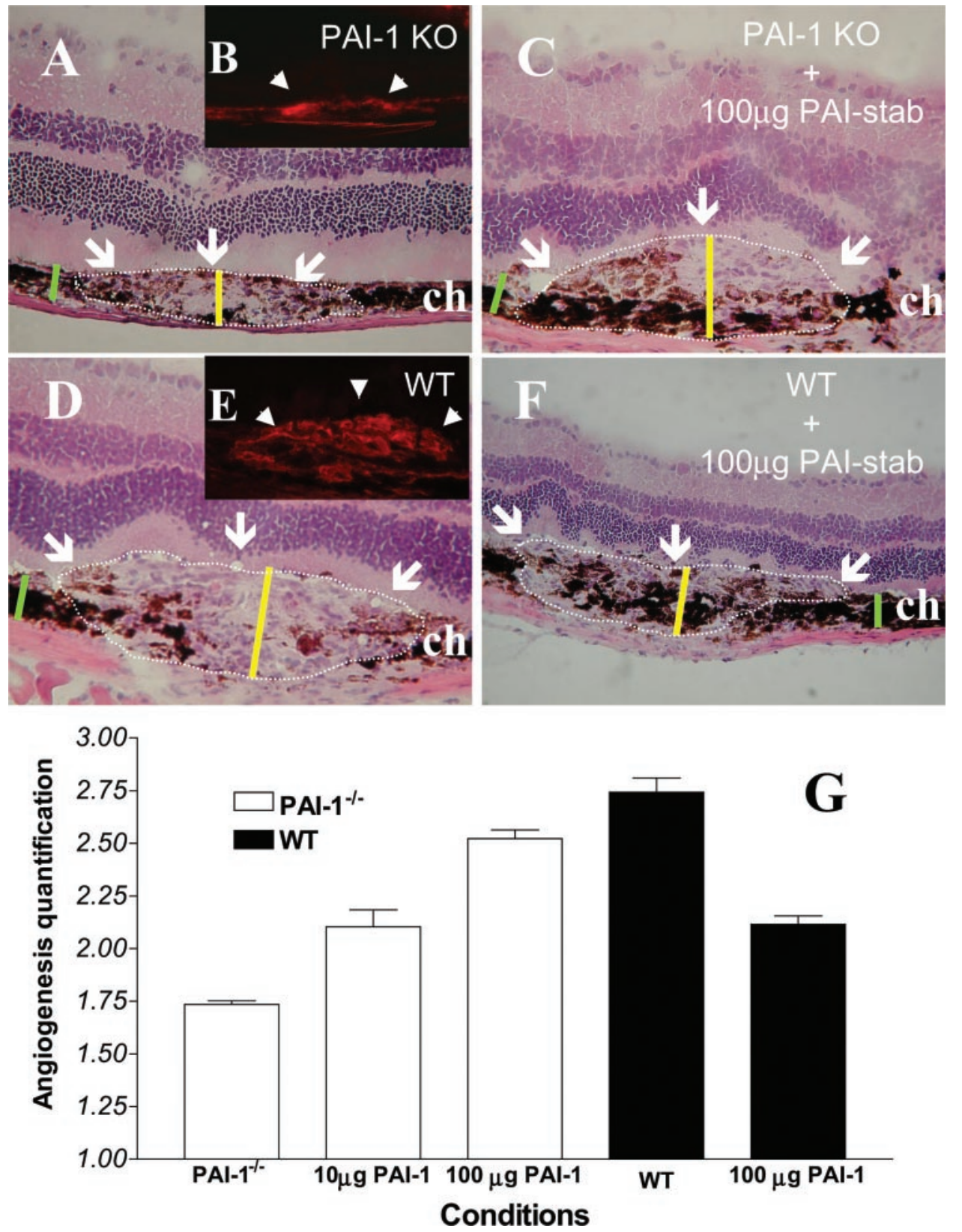

Figure 2. Dose-dependent effects of PAI-1 on choroidal neovascular reaction. Histologic analysis and immunofluorescence of new vessels (detected in red with anti-PECAM antibodies) in PAI-1 ${ }^{-/}$and WT mice treated with high doses of recombinant PAI-1 or vehicle only (A-F). Hematoxylin-eosin staining of a representative area showing, restricted choroidal reaction at the site of laserinduced trauma in $\mathrm{PAI}-1^{-/-}$mice treated with vehicle only (A) and increasing restoration of $\mathrm{CNV}$ in PAI$1^{-/-}$animals treated with $100 \mu \mathrm{g} / \mathrm{d}$ active PAI-1 (C). On the contrary, reduced angiogenesis in WT control mice treated with high doses of active PAI-1 $(100 \mu \mathrm{g} / \mathrm{d}$, F) compared with WT mice treated with vehicle injection only (D). The neovascular reaction was determined by evaluating the $\mathrm{B} / \mathrm{C}$ ratio as described previously ${ }^{9,10}(\mathbf{G})$. A dose-response effect was observed with daily injection of active PAI-1 in PAI-1 ${ }^{-1-}$ mice, with the higher dose $(100 \mu \mathrm{g})$ nearly restoring the WT pattern. In contrast, a significant inhibitory effect on CNV development was observed when WT mice were treated with a high dose of active PAI-1 $(P<0.001)$. Error bars, SE; the choroidal layer $(\mathrm{ch})$ is indicated, and the neovascular area is delineated. Arrows: area of laser impact. Yellow bars refer to $\mathrm{B}$ and green bars to $\mathrm{C}$, used for the calculation of mean $\mathrm{B} / \mathrm{C}$ ratio for each laser impact. Original magnification, $\times 400$. ing, on serial sections, the maximum height of the lesion above the choroidal layer observed in neighboring intact zones (Figs. $2 \mathrm{~A}-\mathrm{F})$. CNV at the site of laser-induced trauma was very restricted or absent in PAI-1 ${ }^{-/-}$mice (Fig. 2A), but increased with daily injections of 10 (not shown) or $100 \mu \mathrm{g}$ recombinant PAI-1 protein (Fig. 2C). The opposite effect was observed with daily treatment of WT mice (Fig. 2D) with high doses of recombinant PAI-1 (Fig. 2F). A dose-response effect was measured with increasing concentrations of active recombinant PAI-1 (PAI-1-stab, 10 or $100 \mu \mathrm{g} / \mathrm{d}$ ) in PAI-1 ${ }^{-/-}$mice (Fig. 2G). In WT animals, an approximate $35 \%$ reduction of the $\mathrm{B} / \mathrm{C}$ ratio was consistently observed when the mice were treated with high doses of rPAI-1 $(P<0.001)$ compared with placebo (vehicle alone).

\section{Mechanisms by which PAI-1 Promotes Choroidal Angiogenesis}

Complete absence of fibrinogen/fibrin was evident in PAI-1 ${ }^{-/-}$ mice, compatible with excessive fibrinolytic activity owing to the lack of inhibition of uPA and tPA (Fig. 3A). Fibrinogen/ fibrin staining was normally present in the WT control (Fig. $3 \mathrm{~B})$, whereas massive accumulation of fibrinogen/fibrin occurred both in WT and PAI-1 ${ }^{-/-}$mice injected with high doses of recombinant PAI-1, demonstrating a severe inhibition of the plasminogen activator system (Figs. 3C, 3D).

To evaluate the relative influence of the other mechanism of action of PAI-1 (the effect on cellular migration through binding on vitronectin), PAI-1 $1^{-/-}$mice were either injected with $100 \mu \mathrm{g}$ PAI-1-stab-Q123K (IP daily injection), or with AdCMVPAI-1 ${ }^{\mathrm{Q} 123 \mathrm{~K}}$ (intravenous injection on day 1 after laser treatment). The negative and positive controls in each experimental group were the extreme conditions (deficient PAI-1 mice treated with vehicle/AdRR5 and restored WT phenotype with $100 \mu \mathrm{g}$ PAI-1-stab/AdCMVPAI-1). Daily injection of PAI-1stab-Q123K completely restored the CNV pattern observed with PAI-1-stab $(P=0.73$, Fig. $4 \mathrm{~A})$. The adenoviral construct that exhibited a reduced affinity for vitronectin, restored the phenotype observed in PAI-1 ${ }^{-/-}$animals infected with AdCMVPAI-1 ( $P=0.03$, Fig. 4B). 

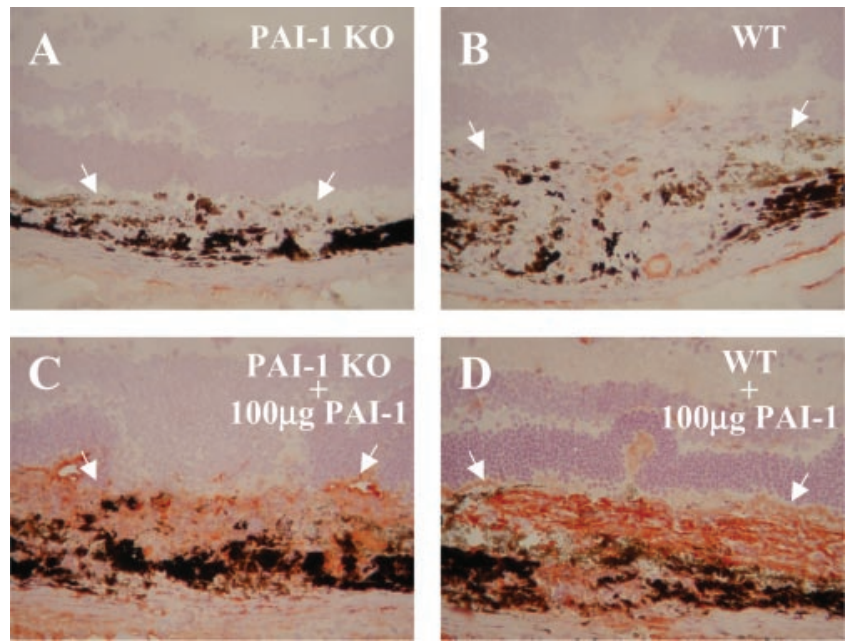

FIGURE 3. Immunolocalization of fibrinogen/fibrin at the site of laserinduced CNV. Frozen ocular sections from control PAI-1 ${ }^{-/-}$(A) or WT mice (B) compared with animals treated with $100 \mu \mathrm{g}$ recombinant PAI-1 (C, D) reveal the absence of fibrin (stained with AEC) in PAI-1 ${ }^{-/}$ and limited amounts in WT mice contrasting with the accumulation of fibrin in animals treated with a high dose of recombinant PAI-1. Original magnification, $\times 400$.

\section{Discussion}

The spatial and temporal profiles of PAI-1 mRNA expression reported in this study are in line with previous observations demonstrating the induction of PAI-1 expression in migrating endothelial cells, an expression limited to the ciliary epithelium in the rodent intact eye, and our own previous results immunolocalizing PAI-1 protein to $\mathrm{CNV}$. 9,26,27

The consistent expression of PAI-1 in human neovascular membranes suggests a role for PAI- 1 during the progression of the exudative form of AMD. Clinically, elevated PAI-1 levels are observed in human diabetic retinopathy, with minimal levels in normal retinas. ${ }^{28}$ Another potential correlation comes from the role of age as an independent risk factor not only for human $\mathrm{AMD}^{29}$ but also for experimental CNV. ${ }^{30}$ A senescence-dependent upregulation of PAI-1 expression has been reported in human vascular endothelial cells ${ }^{31}$ or fibroblasts, ${ }^{32}$ whereas another serpin, pigment-epithelium derived factor, which is a strong inhibitor of angiogenesis, ${ }^{33}$ was downregulated in older RPE. $^{34}$

To our knowledge, this is the first report of a dosedependent PAI-1 effect on angiogenesis in a model related to pathologic conditions of the retina. By testing different concentrations of IP-injected active rPAI-1, we provide clear evidence for dose-dependent opposite effects of PAI-1 during CNV development. The proangiogenic effect of PAI-1 at low concentrations and its antiangiogenic action at high concentrations are supported by the facts that (1) CNV formation was inhibited in PAI-1 ${ }^{-/-}$mice (Lambert et al. ${ }^{9}$ and the present study); (2) CNV formation was restored in PAI-1 ${ }^{-/-}$mice by injecting $\mathrm{rPAI}-1$, and the level of restoration was proportional to the injected dose; (3) injection of high dose of rPAI-1 (100 $\mu \mathrm{g} /$ day) into WT mice significantly inhibited development of $\mathrm{CNV}$.

\section{A}

\section{B}

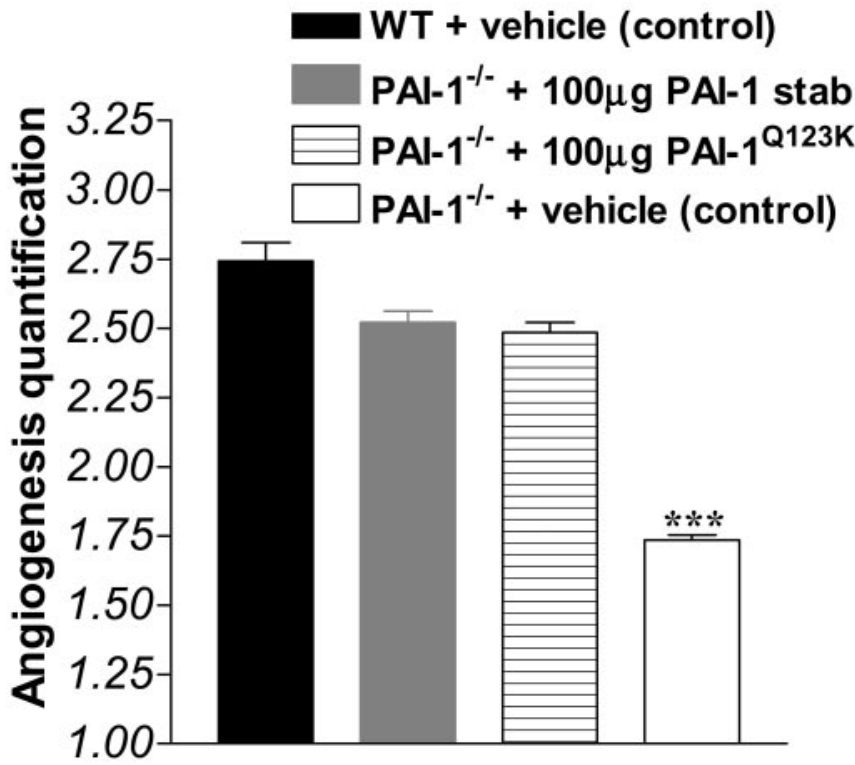

Conditions

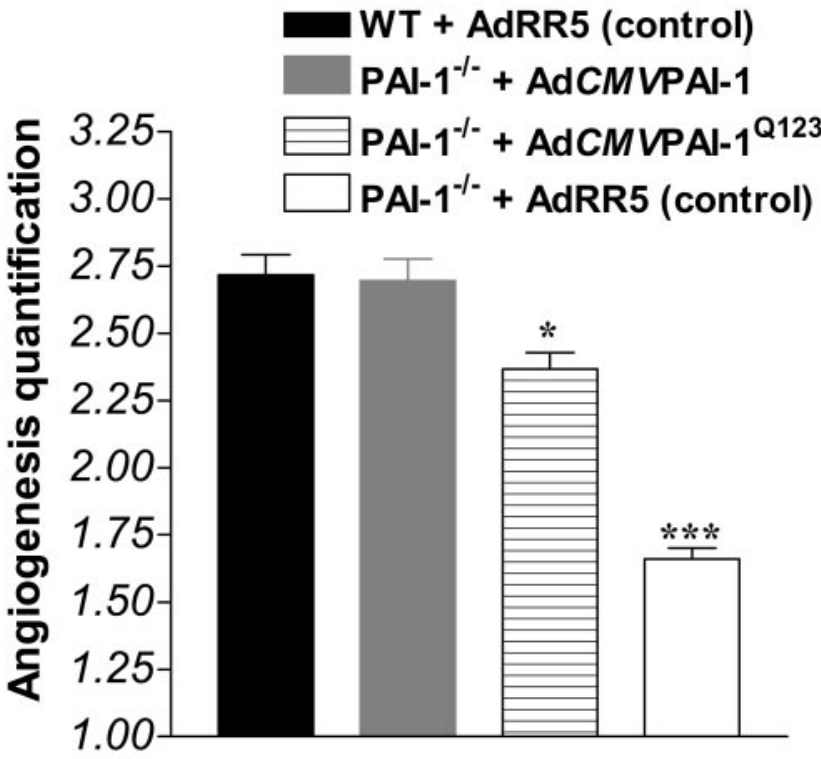

Conditions

FIGURE 4. Injection of rPAI-1, defective in vitronectin binding, restored the angiogenic phenotype. PAI-1 ${ }^{-/-}$mice were injected either with (A) mutated PAI-1 protein (daily injection of $100 \mu \mathrm{g}$ PAI-1-stab-Q123K) or with (B) recombinant adenoviruses bearing the mutated human PAI-1 gene (single intravenous injection of AdCMVPAI-1 ${ }^{\mathrm{Q} 123 \mathrm{~K}}$ on day 1 after laser treatment). For each condition, appropriate positive (injection of the same dose of PAI-1-stab/injection of AdCMVPAI-1) and negative controls (injection of vehicle only or injection of AdRR5) were performed. Quantification of CNV based on image analysis with calculation of the $\mathrm{B} / \mathrm{C}$ ratio for each laser wound revealed that the mutant proteins defective for vitronectin binding restored a $\mathrm{B} / \mathrm{C}$ ratio equal $(P=0.73$ in $\mathbf{A})$ or very similar $(P=0.03$ in $\mathbf{B})$ to that with intact $\mathrm{PAI}-1$ proteins. ${ }^{*} P<0.05 ; * * * P<0.001 ;$ error bars, SE. 
The colocalization of uPA and PAI-1 on migrating endothelial $^{26}$ and tumoral cells ${ }^{35}$ points out the importance of simultaneous production of both proteases and inhibitors and leads to the concept of "proteolytic balance. "By protecting the extracellular matrix (ECM) against excessive degradation, PAI-1 may serve to stabilize the matrix scaffold required for endothelial cell migration and the coordinated assembly of endothelial cells into capillaries. ${ }^{36}$ Along with other adhesive glycoproteins, the deposition of fibrinogen/fibrin serves as a scaffold to support binding of growth factors and to promote the cellular responses of adhesion, proliferation, and migration during angiogenesis. ${ }^{37}$ The intense modulation of fibrinogen/fibrin deposition induced with variations of the levels of PAI-1 was demonstrated in our model of experimental CNV by immunohistochemical localization (Fig. 3).

To separate the contribution of PAI-1 protease inhibitory activity from its vitronectin-binding properties involved in the control of cell migration,,$^{7,8}$ we injected PAI-1 ${ }^{-/-}$mice with recombinant mutated PAI-1 protein defective in vitronectin binding or with adenoviruses expressing the mutant. The injected or endogenously expressed mutated forms both significantly restored the choroidal pathologic reaction, indicating that plasminogen activator inhibition by PAI-1 is probably the major mechanism of action involved in the promotion of angiogenesis. A complementary approach to demonstrate a minimal influence of vitronectin binding properties of PAI-1 would necessitate the induction of our experimental model in vitronectin-deficient mice. Together with our previous work demonstrating the influence of UPA, tPA, and plasminogen deficiency, ${ }^{38}$ these new observations nevertheless point out the importance of fibrinolysis during the development of choroidal neovascularization.

Most important, our data explain, at least in part, the dosedependent efficiency of a drug such as anecortave acetate, already in use in clinical trials for the exudative form of AMD. The inhibition of uPA expression is likely to be beneficial. ${ }^{38}$ However, increased dosage of the agent may increase local expression of PAI-1 without reaching the high levels necessary for the inhibition of angiogenesis. This discrepancy was indeed observed with the higher dosage of anecortave $(30 \mathrm{mg}$ ) that was ineffective compared with placebo. ${ }^{25}$

The existence of biphasic dose/response curves warns against uncontrolled pharmacological strategies in which PAI-1 agonists/antagonists are used for inhibition of $\mathrm{CNV}{ }^{39}$

\section{Acknowledgments}

The authors thank Laurent Naa and Fabrice Olivier for their collaboration and Patricia Gavitelli for technical assistance.

\section{References}

1. Bajou K, Noël A, Gerard RD, et al. Absence of host plasminogen activator inhibitor 1 prevents cancer invasion and vascularization. Nat Med. 1998;4:923-928.

2. Gutierrez LS, Schulman A, Brito-Robinson T, Noria F, Ploplis VA, Castellino FJ. Tumor development is retarded in mice lacking the gene for urokinase-type plasminogen activator or its inhibitor, plasminogen activator inhibitor-1. Cancer Res. 2000;60:58395847.

3. Ploplis VA, Carmeliet P, Vazirzadeh S, Van Vlaenderen I, Moons L, Plow EF. Effects of disruption of the plasminogen gene on thrombosis, growth, and health in mice. Circulation. 1995;92:25852593.

4. Andreasen PA, Egelund R, Petersen HH. The plasminogen activation system in tumor growth, invasion, and metastasis. Cell $\mathrm{Mol}$ Life Sci. 2000;57:25-40.

5. Ploplis VA, French EL, Carmeliet P, Collen D, Plow EF. Plasminogen deficiency differentially affects recruitment of inflammatory cell populations in mice. Blood. 1998;91:2005-2009.
6. Rakic JM, Maillard C, Jost M, et al. Role of plasminogen activator plasmin system in tumor angiogenesis. Cell Mol Life Sci. 2003;60: 463-473.

7. Waltz DA, Natkin LR, Fujita RM, Wei Y, Chapman HA. Plasmin and plasminogen activator inhibitor type 1 promote cellular motility by regulating the interaction between the urokinase receptor and vitronectin. J Clin Invest. 1997;100:58-67.

8. Stefansson S, Lawrence DA. The serpin PAI-1 inhibits cell migration by blocking integrin alpha $\mathrm{V}$ beta 3 binding to vitronectin. Nature. 1996;383:441-443.

9. Lambert V, Munaut $\mathrm{C}$, Noel A, et al. Influence of plasminogen activator inhibitor type I on choroidal neovascularization. FASEB J. 2001; 15:1021-1027.

10. Lambert V, Munaut C, Jost M, et al. Matrix metalloproteinase-9 contributes to choroidal neovascularization. Am J Patbol. 2002; 161:1247-1253.

11. Soff GA, Sanderowitz J, Gately S, et al. Expression of plasminogen activator inhibitor type 1 by human prostate carcinoma cells inhibits primary tumor growth, tumor associated angiogenesis, and metastasis to lung and liver in an athymic mouse model. J Clin Invest. 1995;96:2593-2600.

12. Penn JS, Rajaratnam VS, Collier RJ, Clark AF. The effect of an angiostatic steroid on neovascularization in a rat model of retinopathy of prematurity. Invest Ophthalmol Vis Sci. 2001;42:283-290.

13. Blei, F, Wilson, EL, Mignatti, P, Rifkin, DB. Mechanism of action of angiostatic steroids: suppression of plasminogen activator activity via stimulation of plasminogen activator inhibitor synthesis. $\mathrm{J}$ Cell Pbysiol. 1993;155:568-578.

14. DeFaller JM, Clark AF. A new pharmacological treatment for angiogenesis. In: Taylor HR, ed. Pterygium. The Hague: Kugler Publications; 2000:159-181.

15. Soubrane G, De Smet MD, Schmidt-Erfurth U, et al. Anecortave acetate for the treatment of AMD patients with subfoveal choroidal neovascularization (CNV). Ophthalmic Res. 2002;34:3312.

16. Devy L, Blacher S, Grignet-Debrus C, et al. The pro- or antiangiogenic effect of plasminogen activator inhibitor is dose dependent. FASEB J. 2002;16:147-154.

17. Stefansson S, Petitclerc E, Wong MK, McMahon GA, Brooks PC, Lawrence DA. Inhibition of angiogenesis in vivo by plasminogen activator inhibitor-1. J Biol Chem. 2001;276:8135-8141.

18. McMahon GA, Petitclerc E, Stefansson S, et al. Plasminogen activator inhibitor-1 regulates tumor growth and angiogenesis. $J$ Biol Chem. 2001;276:33964-33968.

19. Carmeliet P, Kieckens L, Schoonjans L, et al. Plasminogen activator inhibitor-1 gene-deficient mice. I. Generation by homologous recombination and characterization. J Clin Invest. 1993;92:27462755.

20. Tobe T, Ortega S, Luna JD, et al. Targeted disruption of the FGF2 gene does not prevent choroidal neovascularization in a murine model. Am J Patbol. 1998;153:1641-1646.

21. Nar H, Bauer M, Stassen JM, Lang D, Gils A, Declerck PJ. Plasminogen activator inhibitor 1: structure of the native serpin, comparison to its other conformers and implications for serpin inactivation. J Mol Biol. 2000;297:683-695.

22. Gils A, Knockaert I, Declerck PJ. Substrate behavior of plasminogen activator inhibitor- 1 is not associated with a lack of insertion of the reactive site loop. Biochemistry. 1996;35:7474-7481.

23. Gerard RD, Meidell RS. Adenovirus vectors. In: Hames BD, Glovers D, eds. DNA Cloning: A Practical Approach: Mammalian Systems. Oxford, UK: Oxford University Press; 1995:285-307.

24. Carmeliet P, Moons L, Lijnen R, et al. Inhibitory role of plasminogen activator inhibitor-1 in arterial wound healing and neointima formation: a gene targeting and gene transfer study in mice. Circulation. 1997;96:3180-3191.

25. Behringer RR, Crotty DA, Tennyson VM, Brinster RL, Palmiter RD, Wolgemuth DJ. Sequences $5^{\prime}$ of the homeobox of the Hox-1.4 gene direct tissue-specific expression of lacZ during mouse development. Development. 1993;117:823-833.

26. Pepper MS, Sappino AP, Montesano R, Orcin L, Vassalli JD. Plasminogen activator inhibitor-1 is induced in migrating endothelial cells. J Cell Pbysiol. 1992;153:129-139. 
27. Masos T, Dan JA, Miskin R. Plasminogen activator inhibitor-1 mRNA is localized in the ciliary epithelium of the rodent eye. Invest Opbthalmol Vis Sci. 2000;41:1006-1011.

28. Grant MB, Ellis EA, Caballero S, Mames RN. Plasminogen activator inhibitor-1 overexpression in nonproliferative diabetic retinopathy. Exp Eye Res. 1996;63:233-244.

29. Hyman L, Neborsky R. Risk factors for age-related macular degeneration: an update. Curr Opin Opbthalmol. 2002;13:171175 .

30. Espinosa-Heidmann DG, Suner I, Hernandez EP, Frazier WD, Csaky $\mathrm{KG}$, Cousins SW. Age as an independent risk factor for severity of experimental choroidal neovascularization. Invest Opbthalmol Vis Sci. 2002;43:1567-1573.

31. Comi P, Chiaramonte R, Maier JA. Senescence-dependent regulation of type 1 plasminogen activator inhibitor in human vascular endothelial cells. Exp Cell Res. 1995;219:304-308.

32. Mu XC, Higgins PJ. Differential growth state-dependent regulation of plasminogen activator inhibitor type-1 expression in senescent IMR-90 human diploid fibroblasts. J Cell Physiol. 1995;165:647657.
33. Dawson DW, Volpert OV, Gillis P, et al. Pigment epitheliumderived factor: a potent inhibitor of angiogenesis. Science. 1999; 285:245-248.

34. Tombran-Tink J, Shivaram SM, Chader GJ, Johnson LV, Bok D. Expression, secretion, and age-related downregulation of pigment epithelium-derived factor, a serpin with neurotrophic activity. J Neurosci. 1995;15:4992-5003.

35. Liu G, Shuman MA, Cohen RL. Co-expression of urokinase, urokinase receptor and PAI-1 is necessary for optimum invasiveness of cultured lung cancer cells. Int J Cancer. 1995;60:501-506.

36. Pepper MS, Montesano R. Proteolytic balance and capillary morphogenesis. Cell Differ Dev. 1990;32:319-327.

37. Simpson-Haidaris PJ, Rybarczyk B. Tumors and fibrinogen: the role of fibrinogen as an extracellular matrix protein. Ann NY Acad Sci. 2001;936:406- 425 .

38. Rakic JM, Lambert V, Munaut C, et al. Mice lacking the uPA, tPA or plasminogen genes are resistant to experimental choroidal neovascularization. Invest Ophthalmol Vis Sci. 2003;44:1732-1739.

39. Calabrese EJ. Estrogen and related compounds: biphasic dose responses. Crit Rev Toxicol. 2001;31:503-515. 